\title{
Involvement of YAP and LATS1 in lung development in a rat model of nitrofen-induced congenital diaphragmatic hernia
}

\author{
Junzuo Liao1, Wenying Liu ${ }^{1,2 *}$, Libin Zhang1, Qin Li ${ }^{1}$, Fang Hou ${ }^{1}$ \\ ${ }^{1}$ Department of Pediatric Surgery, Sichuan Academy of Medical Sciences \& Sichuan Provincial People's Hospital, School of \\ Medicine, University of Electronic Science and Technology of China, ${ }^{2}$ Institute of Laboratory Animais of Sichuan Academy of \\ Medical Sciences \& Sichuan Provincial People's Hospital, Chengdu City, China
}

*For correspondence: Email: vpvpe7@163.com

Sent for review: 26 November 2019

Revised accepted: 25 February 2020

\begin{abstract}
Purpose: To investigate the role of Hippo pathway in lung development in congenital diaphragmatic hernia $(C D H)$.

Methods: One oral dose of nitrofen was maternally administered for induction of CDH on embryonic day 9.5 (E 9.5). Sildenafil was administered intragastrically at a dose of $100 \mathrm{mg} / \mathrm{kg}$ on E 11.5. Three rat groups were used: control, $C D H$, and $C D H$ + sildenafil. Cesarean section was used for fetal delivery on E 21.5. Fetuses with left diaphragmatic hernia (except in control rats) were chosen for investigations. Fetal body weight and weight of lung tissue were recorded, and lung histological evaluation, western blot and PCR were carried out after lung processing.

Results: There was markedly higher expression of YAP in $C D H$ rats than in control rats was unaffected by antenatal sildenafil administration $(p<0.05)$. However, prenatal sildenafil intervention significantly increased LATS1 expression in the lung of CDH fetuses $(p<0.05)$.

Conclusion: These results indicate that increased pulmonary YAP expression in $C D H$ rat model might contribute to pulmonary vascular remodeling and suppression of lung development. Thus, antenatal sildenafil administration not only mitigates abnormal vascular remodeling but also promotes lung development, most likely via increased expression of LATS1.
\end{abstract}

Keywords: Congenital diaphragmatic hernia (CDH), Hippo pathway, Lung development, Sildenafil

\begin{abstract}
This is an Open Access article that uses a fund-ing model which does not charge readers or their institutions for access and distributed under the terms of the Creative Commons Attribution License (http://creativecommons.org/licenses/by/4.0) and the Budapest Open Access Initiative (http://www.budapestopenaccessinitiative.org/read), which permit unrestricted use, distribution, and reproduction in any medium, provided the original work is properly credited.

Tropical Journal of Pharmaceutical Research is indexed by Science Citation Index (SciSearch), Scopus, International Pharmaceutical Abstract, Chemical Abstracts, Embase, Index Copernicus, EBSCO, African Index Medicus, JournalSeek, Journal Citation Reports/Science Edition, Directory of Open Access Journals (DOAJ), African Journal Online, Bioline International, Open-J-Gate and Pharmacy Abstracts
\end{abstract}

\section{INTRODUCTION}

Congenital diaphragmatic hernia $(\mathrm{CDH})$ is a disease caused by abnormal embryonic development $[1,2]$. Studies have shown that mortality caused by $\mathrm{CDH}$ is still as high as $40-$ $60 \%[3,4]$. At present, it is believed that the primary basis of high death rate in $\mathrm{CDH}$ children involves lack of effective treatment for pulmonary hypoplasia $(\mathrm{PH})$ and persistent pulmonary hypertension (PPH) [2].

Sildenafil relieves pulmonary hypertension [5] and positively affects pulmonary vascular remodeling associated with pulmonary hypertension [6]. Therefore, sildenafil is applied 
clinically in the management of clinical treatment of pulmonary hypertension [7]. Recently, researchers have used sildenafil as a prenatal intervention in animal model of $\mathrm{CDH}$, and found that it had positive therapeutic value in relieving $\mathrm{PH}$, improving pulmonary vascular remodeling [8], and promoting lung development.

The YAP, TAZ and LATS1 are the major components of the Hippo pathway [9]. The Hippo signaling pathway plays an important role in lung development [10]. An abnormality in this pathway is not only related to the abnormal development of bronchus and alveoli, but is also closely related to pulmonary hypertension $[11,12]$. In addition, other researchers have reported that the PDE/cGMP/PKG signaling pathway plays an important role in maintaining the properties of prostate cancer stem cells by regulating the Hippo/TAZ pathway [13]. Therefore, it is important to find out whether the effect of antenatal sildenafil intervention on lung development in a rat model of experimental $\mathrm{CDH}$ is related to the Hippo pathway.

\section{EXPERIMENTAL}

\section{Animal model and study design}

The rats are provided by the Institute of Laboratory Animals of Sichuan Academy of Medical Sciences (Chengdu, China). Fifteen adult female Sprague-Dawley rats weighing between 210 and $250 \mathrm{~g}$ (mean weight $=237 \mathrm{~g}$ ) were used. The rats were mated overnight, and the presence of sperm in vaginal smear was confirmed as embryonic day 0.5 (E 0.5). A total of 14 pregnant rats were randomly divided into control, $\mathrm{CDH}$ and $\mathrm{CDH}+$ sildenafil groups, each with five rats. Congenital diaphragmatic hernia $(\mathrm{CDH})$ was induced by a single, oral maternal administration of nitrofen $(125 \mathrm{mg}$ in $2 \mathrm{~mL}$ olive oil, on $E$ 9.5. Control rats were given an equivalent amount of oil in place of nitrofen. Starting from E 11.5, the rats in the $\mathrm{CDH}+$ sildenafil group were given sildenafil daily via gavage at a dose of $100 \mathrm{mg} / \mathrm{kg}$ dissolved in $2 \mathrm{ml}$ saline, while rats in the $\mathrm{CDH}$ group were given an equivalent volume of saline only. This research was approved by the Animal Ethical Committee of Sichuan Provincial People's Hospital (approval no. 20193192), and was carried out in line with NIH publication on care of laboratory animals [14]. At D 21.5 (term: 22 days), all pregnant rats were given cesarean delivery under pentobarbital sodium anesthesia, and the fetal rats were sacrificed immediately after weighing. The fetal lungs were removed under anatomic stereoscopic microscopy, and the bilateral diaphragm integrity was carefully checked. The lungs were separated from the bronchi bifurcation into left and right lungs, and the lung weights (LW) were recorded.

\section{Lung preparation}

The lungs were placed in $10 \%$ neutral formaldehyde, fixed at $4^{\circ} \mathrm{C}$ for 48 hours, and then embedded in paraffin for histological analysis. The paraffin-embedded fetal lungs were transversely cut into $5-\mu \mathrm{m}$ sections with a microtome. The sections were stained with hematoxylin and eosin ( $H$ \& $E)$, and elastin histochemical stain. Lung samples to be used for western blot analysis and PCR were kept at $80^{\circ} \mathrm{C}$.

\section{Lung morphometry}

Processed lung sections were stained with $\mathrm{H} \& \mathrm{E}$ and Verhoeff-Van Gieson (VVG) [15]. The sections were then observed under the Olympus BX51 optical microscope. Images were taken with BA200 Digital tri camera microscope camera system, and the following developmental indicators of lung parenchyma and blood vessels were determined with image-pro Plus 6.0: alveolar septum and \% of pulmonary alveolar area $(\% \mathrm{AA})$ per unit area, both of which were calculated through image analysis. Another indicator was percentage of the medial wall thickness (MWT): the thickness values of the walls of small pulmonary arteries (20-60 $\mu \mathrm{m})$ were measured with image analysis software. External diameter (ED), diameter of outer elastic layer, and internal diameter (ID), and diameter of inner elastic layer, were measured, and MWT was calculated as shown in Eq 1.

$\operatorname{MWT}(\%)=\{(E D-$ ID $) / E D\} 100 \ldots \ldots . .(1)$

\section{Immunohistochemistry}

Deparaffinized sections were put in a dyeing tank with $3 \% \mathrm{H}_{2} \mathrm{O}_{2}$ at room temperature for $10 \mathrm{~min}$. After rinsing with PBS, the sections were placed in $0.01 \mathrm{M}$ citrate buffer (ZSGB-BIO, Beijing, China), and heated in a microwave oven to boiling point. Then the microwave was switched off. After $5 \mathrm{~min}$, the heating was repeated. After cooling, the sections were rinsed with PBS and sealed with goat serum sealant at room temperature for 20min. Then, they were incubated overnight at $4{ }^{\circ} \mathrm{C}$ with the following primary antibodies: rabbit anti-YAP antibody (1:500, CST), rabbit anti-TAZ antibody (1:200, Abcam), and rabbit anti-LATs1 antibody (1:300, Proteintech Group). Then, they were rinsed in PBS and incubated with biotinylated $2^{\circ}$ antibody (ZSGB-BIO, Beijing, China) at $37^{\circ} \mathrm{C}$ for $30 \mathrm{~min}$. 
After rinsing with PBS, the sections were stained using a DAB chromogenic kit (ZSGB-BIO, Beijing, China), with hematoxylin as a counterstain. After dehydration, the sections were affixed to glass coverslips with neutral balsam and evaluated under a BA200 Digital triocular microcamera system (Motic China Group Co. Ltd). All antibodies used in this study were diluted in phosphate buffered saline (PBS).

\section{Immunoblotting}

Fetal rat lungs were homogenized in RIPA buffer supplemented with Complete Protease Inhibitor Cocktail tablets (Roche) and phosSTOP Phosphatase Inhibitor Cocktail tablets (Roche). The protein concentrations were measured using BCA Protein Quantitation Kits (Beyotime, China). For gel electrophoresis, equal amount of total protein was denatured in loading buffer (Biosntech), and subjected to $10 \%$ SDS polyacrylamide gel electrophoresis (Abcam). Following transfer of the proteins to PVDF membranes (Hybond, USA), the membranes were blocked in $5 \%$ BSA for $2 \mathrm{~h}$ before incubation overnight at $4{ }^{\circ} \mathrm{C}$ with the primary antibodies against YAP $(1: 500$, CST), TAZ (1:200, Abcam), LATs1 (1:300, Proteintech), pYAP (1:1000, CST) and $\beta$-actin (1:5000, Abcam. After TBST rinsing, incubation with secondary antibody (1:5000, Abcam) was done at room temperature for 2 - $3 \mathrm{~h}$, followed again by rinsing with TBST. Detection was performed with Enhanced Chemiluminescence kit (Thermo, USA). The gel image analysis imaging system (Tanon, China) was used for scanning analysis and the results were expressed as relative expression of the target protein (Eq 2).

RPE $=$ ITP/IIR

where $R P E$ is relative protein expression, ITP is integrated optical density value of target protein and IIR is integrated optical density value of internal reference.

\section{Real-time PCR}

Quantitative real-time PCR was performed as previously described Error! Reference source not found.. Total RNA was extracted with Animal Total RNA Isolation Kit (Foregene Co. Ltd.) and reverse-transcribed using RT Easy ${ }^{\mathrm{TM}}$ ।I (Foregene Co. Ltd). The PCR reactions were performed using Real Time PCR Easy ${ }^{\mathrm{TM}}$ (Foregene Co. Ltd), and samples were analyzed on a Step-One Plus instrument (Applied Biosystems). The sequences of primers (Sangon Biotech) used are shown in Table 1.

\section{Statistical analysis}

Data are presented as mean \pm SD. Statistical analysis was done using SPSS version 17.0. One-way ANOVA was used for the comparison of multiple means, while LSD test was used for homogeneity of variance. Tamhane's T2 test was used for heterogeneity of variance. Values of $p<$ 0.05 were considered statistically significant.

\section{RESULTS}

\section{Incidence of CDH, BW, LW and LW/BW}

The incidence of CHD was determined in the three groups. None of the 68 fetuses in the control group presented with $\mathrm{CDH} ; 49$ out of 72 fetuses $(68.1 \%)$ presented with $\mathrm{CDH}$ in $\mathrm{CDH}$ group, while 47 out of 77 fetuses presented with $\mathrm{CDH}$ in the $\mathrm{CDH}+$ sildenafil group. Incidents of $\mathrm{CHD}$ between $\mathrm{CHD}$ and $\mathrm{CHD}+$ sildenafil rats were comparable. Moreover, body weights were comparable among all groups. Fetuses in $\mathrm{CDH}$ group had significant decreases in LW/BW, when compared to the control. Sildenafil did not increase the LW/BW of fetuses with $\mathrm{CDH}$. These results are shown in Table 2.

Table 1: Primer and base sequences

\begin{tabular}{lll}
\hline Primer & Forward & Reverse \\
\hline 3-actin & GAAGATCAAGATCATTGCTCCT & TACTCCTGCTTGCTGATCCA \\
LAts1 & TCGGCAACCACCACCACCATATCCT & CTGTTCCTGTTCGGCACCATCATCGT \\
TAZ & AACTCCGCCACATCTGGAACCTGAAG & TGACACTCAGCAATCAGCCGTCCAAT \\
YAP & CGACTCCTTCTTCAAGCCGCCTGAG & AGCCTGCTGGCAATGGTACATCATCA \\
\hline
\end{tabular}

Table 2: BW, LW and LW/BW of rats in the 4 groups

\begin{tabular}{|c|c|c|c|c|}
\hline Group & $\mathbf{n}$ & BW (g, mean $\pm S D)$ & LW (mg, mean $\pm S D)$ & LW/BW (g/g) \\
\hline Control & 68 & $5.38 \pm 0.31$ & $150.82 \pm 15.35$ & $0.0281 \pm 0.0029$ \\
\hline $\mathrm{CDH}$ & 72 & $5.01 \pm 0.98^{*}$ & $82.77 \pm 13.77^{\#}$ & $0.0196 \pm 0.0038^{\&}$ \\
\hline $\mathrm{CDH}+$ sildenafil & 77 & $5.09 \pm 0.71^{\star *}$ & $87.28 \pm 17.03^{\# \#}$ & $0.0214 \pm 0.0049^{\& \&}$ \\
\hline
\end{tabular}




\section{Lung morphometric analysis}

Rat ED was comparable among the groups. Fetuses in $\mathrm{CDH}$ group had significantly increased values of \% MWT and alveolar septum, and decreased value of $\mathrm{AA} \%$, when compared to the controls. However, treatment with sildenafil significantly improved fetal lung development in the $\mathrm{CDH}$ rat model, but the development still lagged behind that in control rats. These data are shown in Fugre 1 and Table 3.

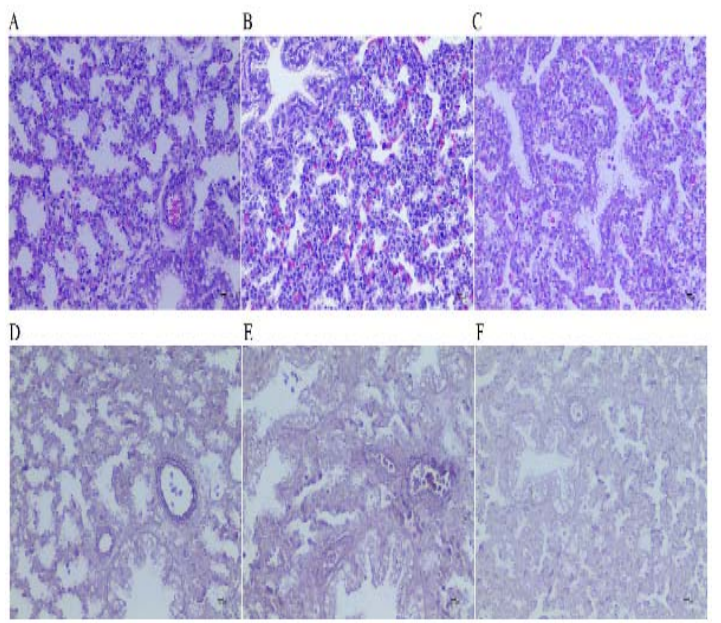

Figure 1: Lungs from $\mathrm{CDH}$ rats (1B) with characteristic features of fetal canalicular stage, relative to lungs of control rats $(1 \mathrm{~A})$ with normal features. The MWT of pulmonary artery was high in $\mathrm{CDH}$ rats (1E), relative to control (1D). Striking occurred in $\mathrm{CDH}+$ sildenafil group, with increases in air saccule size, thin septal walls, and maturation of the pulmonary interstitium (1C), and decreased MWT $(1 \mathrm{~F})$, relative to $\mathrm{CDH}$ rats $(1 \mathrm{~B}, 1 \mathrm{E})(\mathrm{H} \& \mathrm{E}$ : $1 \mathrm{~A}-1 \mathrm{C}$; VVG: $1 \mathrm{D}-1 \mathrm{~F}$, original magnification: $\times 400$, bar $=10$ $\mu \mathrm{m})$

\section{Immunohistochemical expressions of YAP, TAZ and LATS1}

The main sites that stain positive for YAP, TAZ, and LATS1 are bronchiolar and alveolar epithelial tissues in fetal lungs. YAP and LATSI proteins were positively stained in parts of lung mesenchymal and vascular smooth muscle cells (Figure 2).

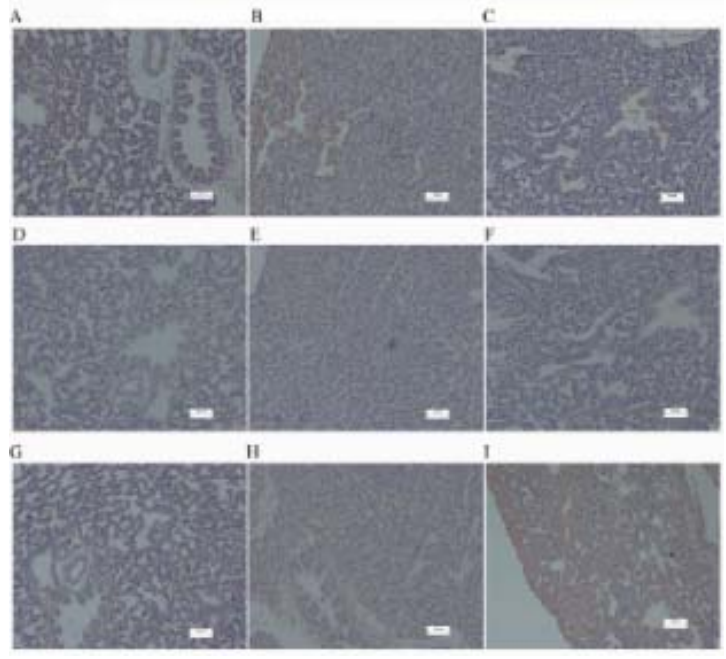

Figure 2: Results of immunohistochemical staining of YAP (2A - 2C), TAZ (2D - 2F), and LATS1 (2G - 2I) in pulmonary sections of control rats (2A, 2D, and $2 \mathrm{G}$ ); $\mathrm{CDH}$ group $(2 \mathrm{~B}, 2 \mathrm{E}$, and $2 \mathrm{H})$, and $\mathrm{CDH}+$ sildenafil rats $(2 \mathrm{C}, 2 \mathrm{~F}$, and $2 \mathrm{I})$. The predominant sites of YAP, TAZ, and LATS1 staining were the bronchiolar and alveolar epithelial tissues in fetal lungs. Positive staining of YAP and LATS1 was also detected in parts of mesenchymal and lung vascular smooth muscle cells. Immunoreactivity of YAP was stronger in the $\mathrm{CDH}$ and $\mathrm{CDH}+$ sildenafil groups than in the control group. The LATS1 immunostaining in the $\mathrm{CDH}+$ sildenafil group was stronger than that in the control and $\mathrm{CDH}$ groups $(\mathrm{bar}=100 \mu \mathrm{m})$

\section{Expressions of YAP, TAZ, LATS1, and p-YAP}

Compared to the control group, an increased YAP expression was seen in the $\mathrm{CDH}$ group. The expressions of TAZ, LATS1, and $p$-YAP in the $\mathrm{CDH}$ group were not significantly different from those in the control group. Compared to $\mathrm{CDH}$ group, an upregulation of LATS1 was shown in $\mathrm{CDH}+$ sildenafil rats, but the expressions of YAP, TAZ and p-YAP were not altered. Equal loading of electrophoresis gels was confirmed by $\beta$-actin staining of the stripped membranes (Figure 3).

Table 3: Lung morphometric analysis

\begin{tabular}{|c|c|c|c|c|c|}
\hline Group & $\mathbf{n}$ & $\begin{array}{c}\text { Alveolar septum } \\
(\mu \mathrm{m})\end{array}$ & AA\% (\%) & $\mathrm{ED}(\mu \mathrm{m})$ & \%MWT (\%) \\
\hline Control & 68 & $13.51 \pm 3.11$ & $63.22 \pm 8.91$ & $27.33 \pm 8.82$ & $11.86 \pm 3.18$ \\
\hline $\mathrm{CDH}$ & 34 & $22.39 \pm 5.89^{*}$ & $40.63 \pm 6.53^{\#}$ & $30.39 \pm 11.23 \S$ & $33.85 \pm 6.94 \%$ \\
\hline $\mathrm{CDH}+$ sildenafil & 39 & $15.70 \pm 3.89^{* *}$ & $55.19 \pm 5.17^{\# \#}$ & $26.78 \pm 7.77 \S \S$ & $15.56 \pm 4.77 * ※$ \\
\hline
\end{tabular}




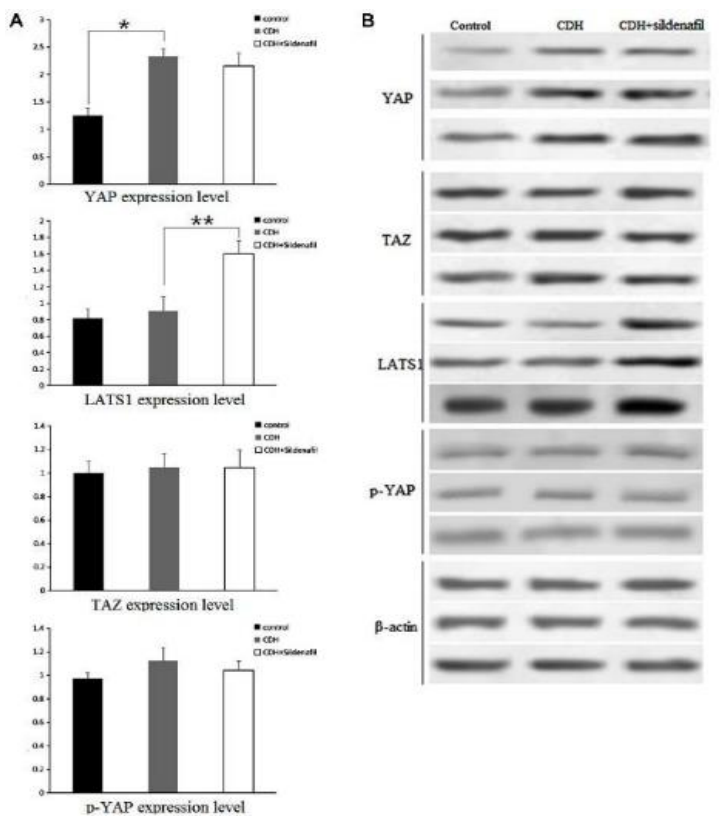

Figure 3: Western blot results showing increased expression of YAP in CDH group, when compared to control lungs. ${ }^{*} P<0.01$, expression of LATS1 in $\mathrm{CDH}$ + sildenafil group vs $\mathrm{CDH}$ rats

Relative mRNA expression levels of YAP, TAZ, and LATS1

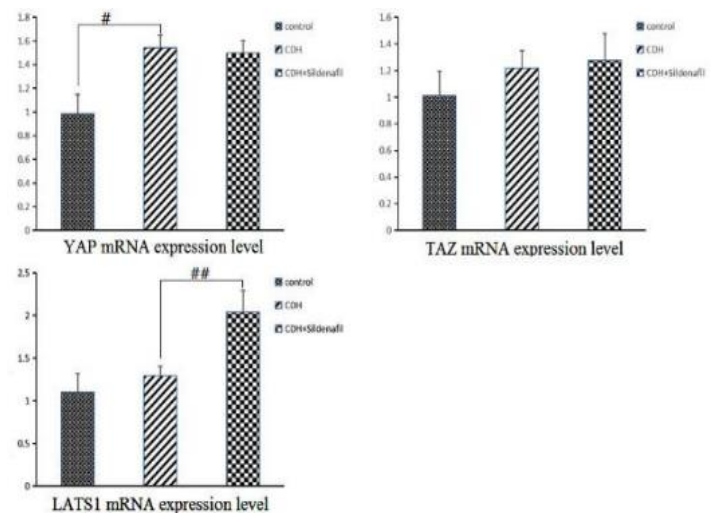

Figure 4: Effect of sildenafil on the relative mRNA expressions of YAP, TAZ, and LATS1 in CDH rats. The relative mRNA expressions of YAP were markedly upregulated in lungs of $\mathrm{CDH}$ rats, relative to control rat lungs ( $\# p<0.05$ ). Compared to $\mathrm{CDH}$ group, sildenafil treatment did not alter YAP mRNA expression in lungs of the $\mathrm{CDH}+$ sildenafil group. There were no significant differences in relative mRNA expression levels of TAZ and LATS1 between the CDH and control groups. Sildenafil treatment significantly increased LATS1 mRNA expression in the CDH + sildenafil group, when compared to $\mathrm{CDH}$ group $\left({ }^{\#} p<\right.$ 0.05)

The relative mRNA expression level of YAP in lungs was markedly upregulated in $\mathrm{CDH}$ rats, relative to control. However, the relative mRNA expression levels of LATS1 and TAZ in CDH group did not change, relative to control group. Compared to CDH group, LATS1 mRNA expression levels were significantly increased in $\mathrm{CDH}+$ sildenafil group. However, YAP and TAZ mRNA expression levels in CDH + sildenafil did not differ significantly from their corresponding expressions in the $\mathrm{CDH}$ group. These data are shown in Figure 4.

\section{DISCUSSION}

Consistent with previous studies, the present investigation has shown that lung pathology in $\mathrm{CDH}$ rats is similar to that in humans. The study also showed that antenatal sildenafil therapy can significantly improve lung development in $\mathrm{CDH}$ rats. It was found that upregulated YAP expression in $\mathrm{CDH}$ rats was associated with increased pulmonary vascular resistance. In mammals, YAP is the key functional effector of Hippo route. On activation, YAP/TAZ undergoes phosphorylation by LATS1/2, resulting in its removal from the nucleus, formation of ubiquitin derivative and proteolysis [16].

This signaling is involved in cardiovascular development, vascular homeostasis and vascular remodeling $[17,18]$. In the studies on pulmonary hypertension, researchers also found that YAP is regulates proliferation and viability of lung arterial vascular smooth muscle cells VSMCs) and pulmonary vascular remodeling [19]. Therefore, it was speculated that pulmonary vessel remodeling and pulmonary hypertension in $\mathrm{CDH}$ were partly due to an increase of YAP expression.

It is known that YAP controls the expressions of factors involved cell proliferation and negative controllers of cell death. Thus, when the Hippo pathway is impaired, organ enlargement results, which is a phenotypical feature of Hippo signal activation [20]. However, in this study, it was found that increased YAP expression in $\mathrm{CDH}$ lungs did not result in increased lung size, but led to a decrease in lung size and a significant halt in development. A recent study suggested that early inactivation of the Hippo pathway during the early stages of lung formation resulted in a sharp decline instead of anticipated increment in pulmonary size $[21,22]$. In the study, the researchers discovered that in spite of the epithelial location of nuclear YAP, Shhcre; Lats mutant rats had impaired lung size. Similar phenotypes have also been reported in renal tissues and saliva of transgenic animals overexpressing YAP or mutants with a LATS1/2 
deletion [23]. Thus, the Hippo pathway plays a major role in maintaining normal epithelial tissue which is critical to organ size [22]. Moreover, increased YAP activity could lead to impaired differentiation and maturation of lung epithelial cells and decreased surfactant proteins, which are in accordance with many disease manifestations of $\mathrm{CDH}$ [24]. These findings suggest that increase in YAP expression may be vital for lung pulmonary growth in $\mathrm{CDH}$ rat model, leading to $\mathrm{PH}$.

In the present study, it was also found that antenatal administration of sildenafil was beneficial for improving $\mathrm{PH}$ and $\mathrm{PPH}$, as evidenced by the alveolar septal thickness, $\% \mathrm{MWT}$, and \%AA in the $\mathrm{CDH}+$ sildenafil group, relative to the $\mathrm{CDH}$ group. Surprisingly, YAP expression and phosphorylation in lung of rats in $\mathrm{CDH}+$ sildenafil group were not affected. Interestingly, it was found that antenatal administration of sildenafil significantly increased LATS1 expression, when compared with $\mathrm{CDH}$ group. These results suggest that the increased expression level of LATS1 in $\mathrm{CDH}+$ sildenafil group could be related to the improvement of lung development, but the underlying mechanism remains unclear.

The involvement of Hippo pathway in organ size regulation is well known. With intensive research, more and more genes have been found to be involved in the Hippo pathway, and the function of the pathway is being unraveled step by step. It has been found that except for the classical pathway, the Hippo pathway has a very wide range of connections with other signaling pathways at different levels. In this study, the role of Hippo pathway in lung development was investigated in a rat model of $\mathrm{CDH}$ by comparing the expressions of YAP, TAZ and LATS1 in lung tissues of rats in control, $\mathrm{CDH}$ and $\mathrm{CDH}+$ sildenafil groups.

\section{Limitations of the study}

The study has limitations with respect to elucidation of the relationship between the Hippo pathway and the development of lungs in rats with $\mathrm{CDH}$. These limitations need to be addressed in future studies.

\section{CONCLUSION}

Increased YAP expression in the lungs of $\mathrm{CDH}$ rat model might contribute to pulmonary vascular remodeling and suppression of lung development. Antenatal sildenafil administration not only mitigates abnormal vascular remodeling but also promotes lung development, most likely via increased expression of LATS1.

\section{DECLARATIONS}

\section{Acknowledgement}

This study was supported by the Applied Basic Research Project of the Science and Technology Department of Sichuan Province (no. 2017JY0305) and the Chengdu Science and Technology Bureau Technology Benefit People Technology Research and Development Project (no. 2015-HM01-00441-SF). We thank Honghui Jia and Lin Wang for kindly guiding the establishment of animal models. We thank Lin Jiang for assisting with data analysis.

\section{Conflict of interest}

No conflict of interest is associated with this work.

\section{Contribution of authors}

We declare that this work was done by the authors named in this article and all liabilities pertaining to claims relating to the content of this article will be borne by the authors. JZ Liao is first author. WY Liu obtained funding. JZ Liao, $Q$ Li, LB Zhang, and WY Liu designed the study. JZ Liao, Q Li, and LB Zhang collected the data. JZ Liao and $Q \mathrm{Li}$ were involved in data cleaning and verification. JZ Liao and $Q \mathrm{Li}$ analyzed the data. JZ Liao drafted the manuscript. WY Liu, JZ Liao, and $\mathrm{F}$ Hou contributed to the interpretation of the results and critical revision of the manuscript for important intellectual content and approved the final version of the manuscript. All authors read and approved the final manuscript. JZ Liao and WY Liu are the study guarantors.

\section{Open Access}

This is an Open Access article that uses a funding model which does not charge readers or their institutions for access and distributed under the terms of the Creative Commons Attribution License (http://creativecommons.org/licenses/by/ 4.0) and the Budapest Open Access Initiative (http://www.budapestopenaccessinitiative.org/rea d), which permit unrestricted use, distribution, and reproduction in any medium, provided the original work is properly credited.

\section{REFERENCES}

Trop J Pharm Res, March 2020; 19(3): 546 
1. Leeuwen L, Fitzgerald DA. Congenital diaphragmatic hernia. J Paediatr Child Health 2014; 50(3): 667-673.

2. Ameis $D$, Khoshgoo $N$, Keijzer $R$. Abnormal lung development in congenital diaphragmatic hernia. Semin Pediatr Surg 2017; 26(3): 123-128.

3. Harting MT, Lally KP. The congenital diaphragmatic hernia study group registry update. Semin Fetal Neonatal Med 2014; 19(6): 370-375.

4. Wright JC, Budd JL, Field DJ, Draper ES. Epidemiology and outcome of congenital diaphragmatic hernia: a 9year experience. Paediatr Perinat Epidemiol 2011; 25(2): 144-149.

5. Wang RC, Jiang FM, Zheng QL, Li CT, Peng XY, He CY, Luo J, Liang ZA. Efficacy and safety of sildenafil treatment in pulmonary arterial hypertension: a systematic review. Respir Med 2014; 108(3): 531-537.

6. Milara J, Escrivá J, Ortiz JL, Juan G, Artigues E, Morcillo $E$, Cortijo J. Vascular effects of sildenafil in patients with pulmonary fibrosis and pulmonary hypertension: an ex vivo/in vitro study. Eur Respir J 2016; 47(6): 1737-1749.

7. Unegbu C, Noje C, Coulson JD, Segal JB, Romer L. Pulmonary Hypertension Therapy and a Systematic Review of Efficacy and Safety of PDE-5 Inhibitors. Pediatrics 2017; 139(3): 20161450.

8. Mous DS, Kool HM, Buscop-van Kempen MJ, Koning AH, Dzyubachyk O, Wijnen RMH, Tibboel D, Rottier RJ. Clinically relevant timing of antenatal sildenafil treatment reduces pulmonary vascular remodeling in congenital diaphragmatic hernia. Am J Physiol Lung Cell Mol Physiol 2016; 311(4): 734-742.

9. Dong J, Feldmann G, Huang J, Wu S, Zhang NL, Comerford SA, Gayyed MF, Anders RA, Maitra A, Pan $D$. Elucidation of a universal size-control mechanism in Drosophila and mammals. Cell 2007; 130(6): 11201133.

10. Dai Y, Jablons $D$, You L. Hippo pathway in lung development. J Thorac Dis 2017; 9(3): 2246-2250.

11. He J, Bao Q, Yan M, Liang J, Zhu Y, Wang CJ, Ai D. The role of Hippo/yes-associated protein signalling in vascular remodelling associated with cardiovascular disease. Br J Pharmacol 2018; 175(8): 1354-1361.

12. Yan $D, L i G$, Zhang $Y$. Angiotensin-converting enzyme 2 activation suppresses pulmonary vascular remodeling by inducing apoptosis through the Hippo signaling pathway in rats with pulmonary arterial hypertension. Clin Exp Hypertens 2019; 41(6): 589-598.
13. Liu N, Mei L, Fan X, Tang C, Ji X, Hu XH, Shi W, Qian Y, Hussain M, Wu J, et al. Phosphodiesterase 5/protein kinase $G$ signal governs stemness of prostate cancer stem cells through Hippo pathway. Cancer Lett 2016; 378(1): 38-50.

14. World Health Organization. Principles of laboratory animal care. WHO Chron 1985; 39: 51-56.

15. Percival KR, Radi ZA. A modified Verhoeff's elastin histochemical stain to enable pulmonary arterial hypertension model characterization. Eur J Histochem 2016; 60(1): 2588.

16. Tenbrinck R, Tibboel D, Gaillard JL, Kluth D, Bos AP, Lachmann B, Molenaar JC. Experimentally induced congenital diaphragmatic hernia in rats. $J$ Pediatr Surg 1990; 25(4): 426-429.

17. Meng Z, Moroishi T, Guan KL. Mechanisms of Hippo pathway regulation. Genes Dev 2016; 30: 1-17.

18. Zhou Q, Li L, Zhao B, Guan KL. The hippo pathway in heart development, regeneration, and diseases. Circ Res 2015; 116(1): 1431-1447.

19. He J, Bao Q, Yan M, Liang J, Zhu Y, Wang CJ, Ai D. The role of Hippo/yes-associated protein signalling in vascular remodelling associated with cardiovascular disease. Br J Pharmacol 2018; 175(2): 1354-1361.

20. Pan $D$. The hippo signaling pathway in development and cancer. Dev Cell 2010; 19(4): 491-505.

21. Mo JS, Park HW, Guan KL. The Hippo signaling pathway in stem cell biology and cancer. EMBO Rep 2014; 15(6): 642-656.

22. Nantie LB, Young RE, Paltzer WG, Zhang $Y$, Johnson $R L$, Verheyden $J M$, Sun $X$. Lats1/2 inactivation reveals Hippo function in alveolar type I cell differentiation during lung transition to air breathing. Development 2018; 145(21): 163105.

23. Szymaniak AD, Mi R, McCarthy SE, Gower AC, Reynolds $T L$, Mingueneau M, Kukuruzinska M, Varelas $X$. The Hippo pathway effector YAP is an essential regulator of ductal progenitor patterning in the mouse submandibular gland. Elife 2017; 6: 23499.

24. Otsubo K, Goto $H$, Nishio M, Kawamura K, Yanagi S, Nishie $W$, Sasaki $T$, Maehama $T$, Nishina $H$, Mimori $K$, et al. MOB1-YAP1/TAZ-NKX2.1 axis controls bronchioalveolar cell differentiation, adhesion and tumour formation. Oncogene 2017; 36(29): 4201-4211. 